\title{
THE
}

\section{Fabrication of High-Conductivity, Transparent Electrodes with Trenched Metal Bus Lines}

Otto J. Gregory

University of Rhode Island, ogregory@uri.edu

\author{
R. J. Zeto \\ E. Hryckowian \\ K. A. Burbank
}

Follow this and additional works at: https://digitalcommons.uri.edu/che_facpubs

Part of the Chemical Engineering Commons

Terms of Use

All rights reserved under copyright.

\section{Citation/Publisher Attribution}

Gregory, O. J., Zeto, R. J., Hyckowian, E., \& Burbank, K. A. (1991). Fabrication of High-Conductivity, Transparent Electrodes With Trenched Metal Bus Lines. Journal of the Electrochemical Society, 138(7), 2070-2075. doi: 10.1149/1.2085926

Available at: http://dx.doi.org/10.1149/1.2085926

This Article is brought to you for free and open access by the Chemical Engineering at DigitalCommons@URI. It has been accepted for inclusion in Chemical Engineering Faculty Publications by an authorized administrator of DigitalCommons@URI. For more information, please contact digitalcommons-group@uri.edu. 


\title{
Fabrication of High-Conductivity, Transparent Electrodes with Trenched Metal Bus Lines
}

\author{
O. J. Gregory* \\ Department of Chemical and Materials Engineering, University of Rhode Island, Kingston, Rhode Island 02881
}

R. J. Zeto* and E. Hryckowian*

U.S. Army LABCOM, Electronics Technology and Devices Laboratory, Fort Monmouth, New Jersey 07703

\author{
K. A. Burbank
}

Department of Chemical and Materials Engineering, University of Rhode Island, Kingston, Rhode Island 02881

\begin{abstract}
A novel transparent electrode system has been developed for thin film electroluminescent displays in which the poor conductivity of the indium-tin-oxide (ITO) electrodes has been augmented by high-conductivity buses of thick aluminum or silver. The augmented electrode system consists of patterned ITO electrodes, $200 \mu \mathrm{m}$ wide, centered over narrow aluminum or silver lines $40 \mu \mathrm{m}$ wide and separated by an intermediate diffusion barrier film of titanium to promote adhesion to the ITO and prevent blackening of the main ITO electrode by interfacial reactions. The sheet resistances of the augmented ITO electrodes (Al-Ti-ITO and Ti-Ag-Ti-ITO) were lowered by two orders of magnitude relative to the unaugmented ITO electrodes, yielding absolute values on the order of $0.1 \Omega / \mathrm{s}$.
\end{abstract}

Indium-tin-oxide (ITO) is the most widely used material for the transparent electrodes in alternating current-thin film electroluminescent (ACTFEL) displays (1-3). Speed and brightness uniformity depend critically on ITO line resistance, particularly for large-area displays. Even with integrated ITO lines, a 'zebra' pattern of brightness contrast occurs due to high line resistance. Therefore, to achieve higher conductivity of the transparent electrodes in ACTFEL panels, a structure was developed in which the low-conductivity ITO electrodes were augmented by buses of thick, narrow, high-conductivity metals. Not only would higher conductivity transparent electrodes reduce line delay in larger panels, but they would reduce the power consumption in these low current-high voltage devices and increase the brightness of existing displays by allowing them to be driven at much higher frequencies (4).

Currently, ITO electrodes exhibiting $>85 \%$ transmission in the visible spectrum and sheet resistances of $5-20 \Omega / \square$ are possible, with film thicknesses greater than $500 \mathrm{~nm}$ (5). However, when ITO film thicknesses in the range of 100 $150 \mathrm{~nm}$ are employed, the sheet resistance increases to levels of $30-90 \Omega / \square(6)$. Since sheet resistances on the order of $1 \Omega / \square$ are necessary for large-area displays, only very thick ITO lines will yield the desired properties. This is due in part to the dissipation caused by capacitive currents in highly resistive material. These thick lines lead to dielectric breakdown at the edges of the patterned ITO due to enhanced field effects and poor step edge coverage of the overlying films in the ACTFEL stack (7). A cross section of a typical pixel in an ACTFEL device, indicating where breakdown is likely to occur, is shown in Fig. 1. To avoid premature breakdown at step edges, Ketchpel and Wu (7) employed a thick film aperture layer-bus rail structure for the rear aluminum electrode. A thick film insulator layer, aligned over the step edge, removed the parallel bus rail conductor in this structure from the high electrical field applied to the emitter. Our augmented electrode structure differs from this one in that a trenched metal bus rail was fabricated within the surface layers of the glass.

The augmented electrode structure developed to achieve higher conductivities is shown in Fig. 2. Here, low conductivity ITO electrodes $200 \mu \mathrm{m}$ wide were centered over $40 \mu \mathrm{m}$ wide metal bus lines. The electrode structures evaluated in this study included ITO, Al-ITO, Al-Ti-ITO, Ti-Ag-ITO, and Ti-Ag-Ti-ITO. To prevent interdiffusion of the aluminum/silver and ITO during subsequent heattreatment steps, and to promote adhesion of these metals

* Electrochemical Society Active Member. to the glass and ITO, intermediate thin films of titanium were employed. Blackening of the transparent ITO lines has been observed during the deposition of dielectrics onto ITO (8). Here, the reduction of ITO occurs by displacement reactions with metals that form more stable oxides than indium oxide and tin oxide at the deposition temperature. Consequently, another role of the intermediate barrier film is to minimize the formation of insulating oxide films between the ITO and the bus metallization. These oxide films could lead to undesirable contact resistances and higher sheet resistances for the composite electrode structure.

Titanium was first proposed as a contact material between $\mathrm{Al}$ and $\mathrm{Si}$ in 1972 and was reported to have good diffusion barrier properties (9). However, this titanium metallurgy produced interfacial reactions with $\mathrm{Al}$ which consumed the thin $\mathrm{Ti}$ layers at elevated temperatures and resulted in the formation of $\mathrm{TiAl}_{3}$ intermetallics (10). It was reported in this study that annealing at $500^{\circ} \mathrm{C}$ consumed as much as $1500 \AA$ of titanium in $30 \mathrm{~min}$. In a more recent study of the electrical properties of this Al/Ti contact metallurgy (11), the contact resistance increased with increasing annealing temperatures, suggesting that the growth of this $\mathrm{TiAl}_{3}$ intermetallic layer was a function of time at temperature. Therefore, if a thin layer of titanium is to be used as a diffusion barrier between the aluminum bus metal and ITO, it must be thick enough to survive any subsequent annealing steps.

Historically, the system Ag-Ti and later Ag-Pd-Ti was used extensively as the metallurgy for high-intensity solar

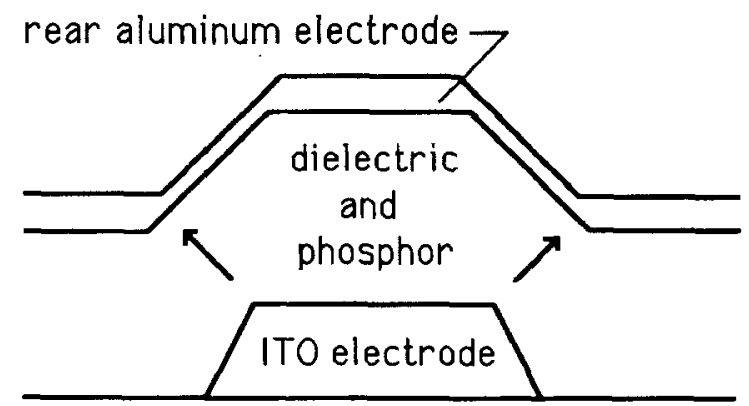

\section{Corning 7059 glass substrate}

Fig. 1. Cross section of an ACTFEL thin film stack at a pixel. 


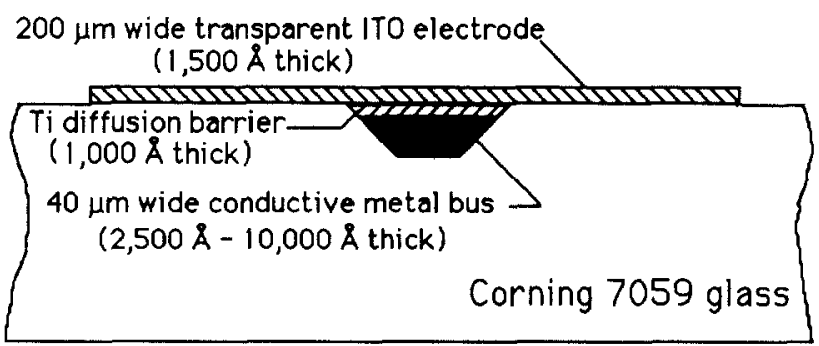

Fig. 2. Cross section of augmented electrode structure formed in Corning 7059 glass.

cell contacts (12-14). Here, the titanium was used to make an adherent contact to silicon by virture of its affinity for oxygen and any native oxides on the silicon. It also served as an effective diffusion barrier to palladium and silver migration. The palladium was used to buffer galvanic corrosion between the titanium and silver layers and thus was not necessary, at least initially, in the present study where a high-conductivity metal bus was used to augment the low conductivity of the ITO lines. A thin titanium layer up to $1500 \AA$ was therefore employed as a diffusion barrier for both the aluminum bus metallizations and the silver bus metallizations used in this study.

The structure shown in Fig. 2, used to achieve higher conductivity transparent electrodes, required trenches for the thick, narrow metal buses to avoid undesirable surface topography and associated breakdown at step edges. Both wet chemical etching and dry etching were used to form the trenches in Corning 7059 glass, a common substrate material used for large-area ACTFEL displays. In this way, the recessed metal lines permitted the use of thinner $1000 \AA$ ITO electrodes, thereby improving the surface topography at ITO step edges and the transmission of light through the electrode. Narrow metal bus lines were employed in this structure to maximize the active pixel area for light emission and yet carry sufficient current to augment the conductivity. With the augmented electrode structure shown in Fig. 2, sheet resistances on the order of $0.1 \Omega / \square$ were achieved, which represents an increase in conductivity of two orders of magnitude relative to the unaugmented electrodes. The processing sequence used to fabricate the augmented ITO electrode structure and the electrical characterization of these novel electrodes are presented.

\section{Experimental}

All thin films including ITO, aluminum, titanium, and silver were deposited by $\mathbf{R F}$ sputtering at room temperature using an MRC Model 822 sputtering system. The titanium diffusion barrier film was deposited directly onto the aluminum and silver bus lines without breaking vacuum to minimize the formation of unwanted oxides between the metals. An ITO sputtering target having a nominal composition of 10 mole percent $(\mathrm{m} / \mathrm{o}) \mathrm{SnO}_{2}$ and $90 \mathrm{~m} / \mathrm{o}$ $\mathrm{In}_{2} \mathrm{O}_{3}$ was obtained from CERAC, Inc., and was used for all ITO depositions. An aluminum sputtering target $99.9999 \%$ pure fabricated by ALCOA, Inc., a titanium sputtering target $99.99 \%$ pure fabricated by MRC, Inc., and a $99.9 \%$ pure silver target were used for all metal depositions.

The titanium was not only used as a barrier film but was also used to promote adhesion to the ITO and to the Corning 7059 glass for the silver metallization. Five different electrode structures were investigated in this study: ITO, Al-ITO, Al-Ti-ITO, Ti-Ag-ITO, and Ti-Ag-Ti-ITO. The augmented electrode structures were vacuum annealed in the load lock of the sputtering chamber, operating at a background pressure of $2 \times 10^{-3}$ torr. Annealing temperatures between 200 and $400^{\circ} \mathrm{C}$ were employed to improve the conductivity of the ITO and stabilize the films.

The glass substrates used in this study were commercially available Corning 7059 electronic grade glass, commonly used for electroluminescent displays. Wet etching of this glass in the as-received condition was initially attempted to produce the trenched structure shown in
Fig. 2. However, nonuniform etch rates and extremely shallow sidewall angles were observed. This etching behavior was attributed to residual stresses that exist within the surface layers of the glass. Consequently, a series of heat-treatments in air was undertaken to relieve these residual stresses. Annealing temperatures between 300 and $700^{\circ} \mathrm{C}$ for $1 \mathrm{~h}$ were investigated for this purpose. An optimal annealing temperature of $650^{\circ} \mathrm{C}$ was obtained to maximize stress relief, minimize phase separation of a barium oxide-rich phase in the glass, and minimize warpage of the glass. The annealing process was therefore used to optimize the sidewall angle of the trench. The optimal annealing temperature produced a trench sidewall angle of $45^{\circ}$, suggesting isotropic etching behavior.

Buffered HF solutions, ranging in composition from 1:2 to $1: 10\left(\mathrm{HF}: \mathrm{NH}_{4} \mathrm{~F}\right)$, were used to produce the trenches in the Corning 7059 glass. Only semiconductor-grade chemicals were used for this purpose. An etching solution of 1:8 $\left(\mathrm{HF}: \mathrm{NH}_{4} \mathrm{~F}\right.$ ) produced etch rates of $100 \mathrm{~nm} / \mathrm{min}$ and trench sidewall angles of $45^{\circ}$, without attacking the positive photoresist and the overhang necessary for lift-off. Augmented electrode structures having trench depths of 0.25 , 0.5 , and $1.0 \mu \mathrm{m}$ were fabricated in this study. Alternatively, argon ion milling was used to trench the glass substrates and obtain vertical sidewalls. Ion milling was conducted in a Veeco $10 \mathrm{in}$. Microetch system, operated at normal beam incidence with substrate rotation. The trench shape, sidewall angles, and dimensions were characterized by scanning electron micrographs (SEMs) taken in cross section and by profilometry.

Trench lines were patterned in positive photoresist on the glass substrate and were used for both trench etching and self-aligned metal deposition. A second mask level was used to define the ITO lines which were centered over the metal bus lines. Prior to spin coating of the AZ 1350J positive photoresist, the glass substrates were cleaned using a standard Corning detergent clean followed by an oxygen plasma clean for approximately $15 \mathrm{~min}$. Spin coating parameters were adjusted to obtain a resist thickness of $2.2 \mu \mathrm{m}$. The following fabrication process was used to produce the augmented electrode structures with selfaligned trenches: ( $i$ ) cleaning of the Corning 7059 glass substrates, (ii) photoresist patterning of the glass for metal trenches-level 1, (iii) wet or dry etching of the patterned glass to form trenches, (iv) trench fill with bus metallization, $(v)$ lift-off of metal, $(v i)$ photoresist patterning of the glass for wide ITO lines - level 2, (vii) ITO deposition, (viii) lift-off of ITO, and $(i x)$ heat-treatment of electrode structure in vacuum.

The test structures used for electrical characterization of the augmented transparent electrodes are shown in Fig. 3a-d. The structures shown in Fig. 3a and c are process
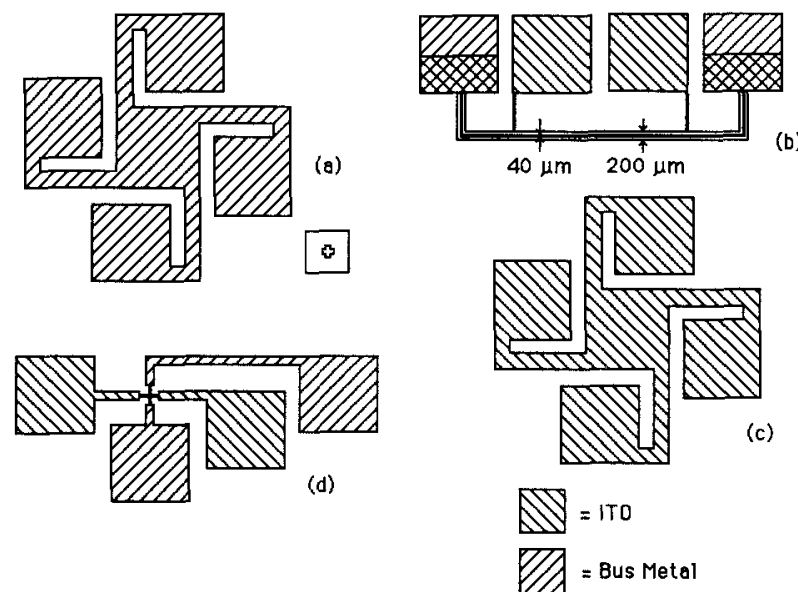

Fig. 3. (a-d) Test patterns used for the electrical characterization of the augmented transparent electrode structures: (a) and (c) are process monitors used to follow sheet resistance of the bus metal and ITO; (b) is the test structure used to determine the sheet resistance of the composite electrode; and (d) is the test structure used to measure the contact resistance between the bus metal and ITO. 
monitors used to follow the sheet resistance of the bus metallization and ITO, respectively. Here, van der Pauw patterns were selected for this purpose. Figure $3 \mathrm{~b}$ shows the four-point test structure used to evaluate the sheet resistance of the composite electrode, and Fig. $3 \mathrm{~d}$ shows the test structure used to evaluate the contact resistance between the bus metal and the ITO. The measured contact area for this test structure was $1.6 \times 10^{3} \mu \mathrm{m}^{2}$. A modified four-point probe technique was used for all sheet resistance determinations.

\section{Results and Discussion}

Process characterization.-The as-received Corning 7059 glass which was used as the substrate material for the augmented electrode structure exhibited considerable residual stress. A rolling process was used to fabricate the 7059 glass, which produced residual compressive stresses in the surface layers of the glass. These stresses manifested themselves in the glass by severe undercutting of the photoresist and enhanced lateral etching. An SEM micrograph of a wet-etched trench formed in the as-received 7059 glass is shown in Fig. 4. Little vertical etching as observed here and a trench sidewall angle of less than $2^{\circ}$ was produced. Subsequent annealing of the as-received glass for one hour at temperatures between 300 and $700^{\circ} \mathrm{C}$ improved the sidewall angle of the trench. An SEM micrograph of a wet-etched trench formed in annealed 7059 glass is shown in Fig. 5. The substrate was annealed in air at $650^{\circ} \mathrm{C}$ for $1 \mathrm{~h}$ prior to etching and resulted in a trench sidewall angle of $45^{\circ}$. This was an optimal annealing condition in that isotropic etching behavior was attained without warpage and phase separation of a barium oxide-rich phase in the glass. An etching solution of $1: 4\left(\mathrm{HF}: \mathrm{NH}_{4} \mathrm{~F}\right)$ was used to optimize the annealing conditions for the Corning 7059 glass. Corning 7059 glass has an annealing point of $630^{\circ} \mathrm{C}$ and a strain point of $593^{\circ} \mathrm{C}$, which was approximately the same condition used here to optimize the sidewall angle of the etched substrates.

However, these concentrated buffered HF etching solutions attacked the photoresist overhang and made subsequent liftoff extremely difficult. A second optimization process was undertaken to produce the desired trench profile without attacking the photoresist overhang, which could be as large as $1 \mu \mathrm{m}$ depending on trench depth. An etching solution of $1: 8\left(\mathrm{HF}: \mathrm{NH}_{4} \mathrm{~F}\right)$ produced etch rates of $100 \mathrm{~nm} / \mathrm{min}$ and $45^{\circ}$ sidewall angles without attacking the photoresist overhang. An SEM micrograph of a wet-etched trench formed in annealed 7059 glass with the photoresist overhang still intact is shown in Fig. 6.

When the Corning 7059 glass substrates were annealed at temperatures greater than $650^{\circ} \mathrm{C}$, some phase separation in this barium borate glass occurred. An optical micrograph of the bottom of a trench formed in 7059 glass that was annealed at $700^{\circ} \mathrm{C}$ is shown in Fig. 7. Here, crystallites were observed in the glass after etching, which can be attributed to either a phase separation/crystallization of a barium oxide-rich phase or an acid-induced crystallization process within the glass itself. In either case, this could

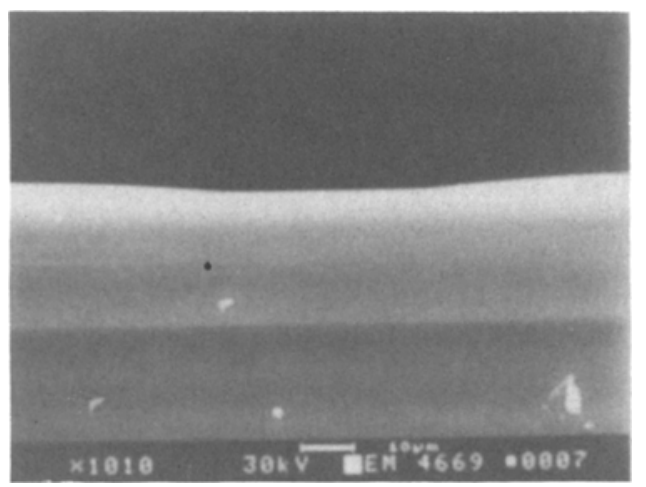

Fig. 4. SEM micrograph of wet-etched trench formed in as-received Corning 7059 glass substrate. Trench profile was produced with $25 \%$ buffered HF solution. Note extremely shallow sidewall angle.

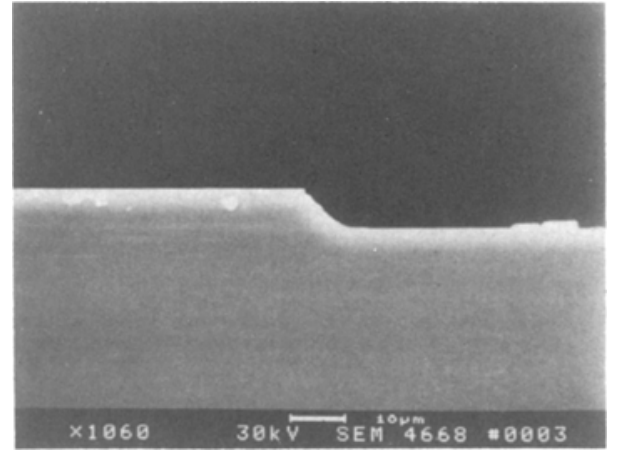

Fig. 5. SEM micrograph of wet-etched trench formed in annealed Corning 7059 glass substrate. Substrate was annealed in air at $650^{\circ} \mathrm{C}$ for $1 \mathrm{~h}$ prior to etching. Trench profile was produced with $25 \%$ buffered $\mathrm{HF}$ solution. Note $45^{\circ}$ sidewall angle.

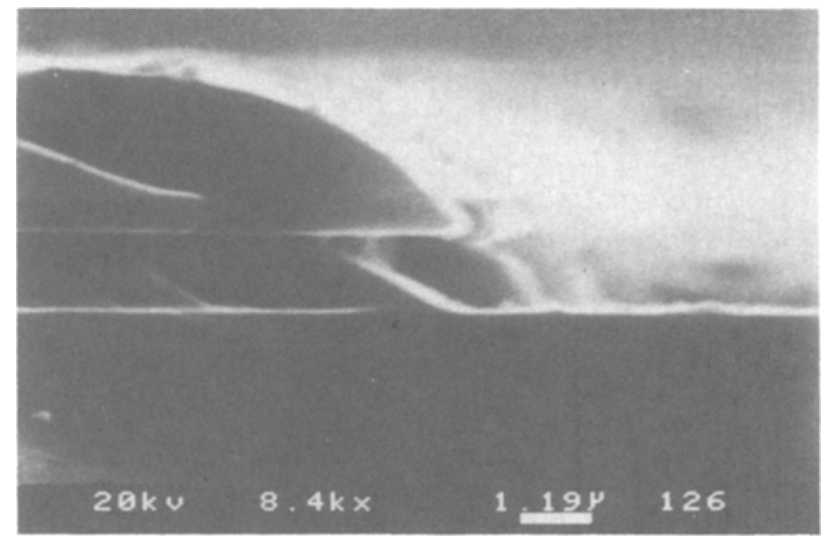

Fig. 6. SEM micrograph of wet-etched trench formed in Corning 7059 glass, showing photoresist overhang intact after etching. Trench profile was produced with a $20 \%$ buffered HF solution.

have a major effect on the surface topography of the overlying bus metal and ITO films and could possibly lead to dielectric breakdown. Therefore, in addition to warpage considerations, excessive annealing temperatures $(T>$ $650^{\circ} \mathrm{C}$ ) should be avoided to prevent undesirable topographies.

Alternatively, argon ion milling was used to trench the glass substrates and obtain vertical sidewalls. An SEM micrograph of an ion-milled trench formed in Corning 7059 glass is shown in Fig. 8. Here, a trench profile with vertical sidewalls was produced without any photoresist over-

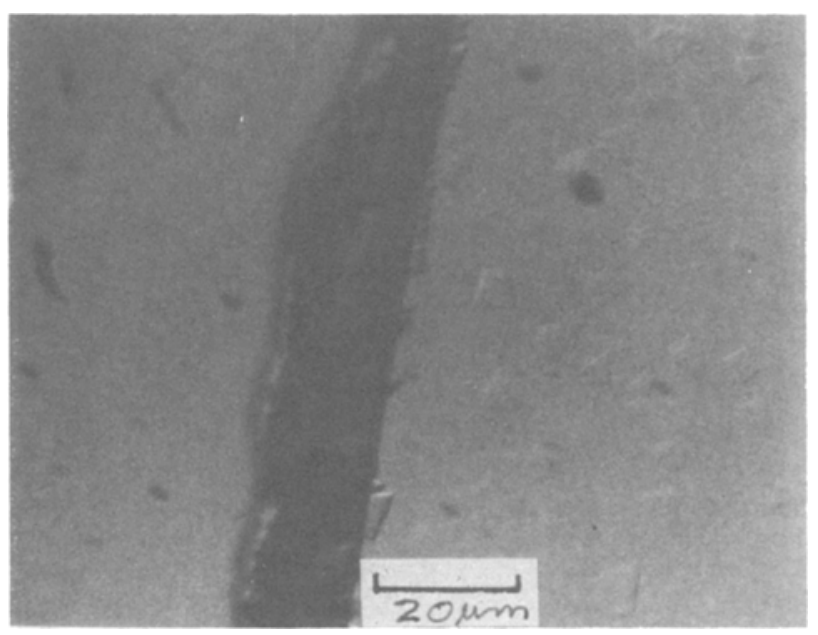

Fig. 7. Optical micrograph of bottom of wet etched trench showing crystallization of glass substrate. Glass was annealed at $700^{\circ} \mathrm{C}$ for $1 \mathrm{~h}$ and etched in $25 \%$ buffered HF solution to produce the trench. 


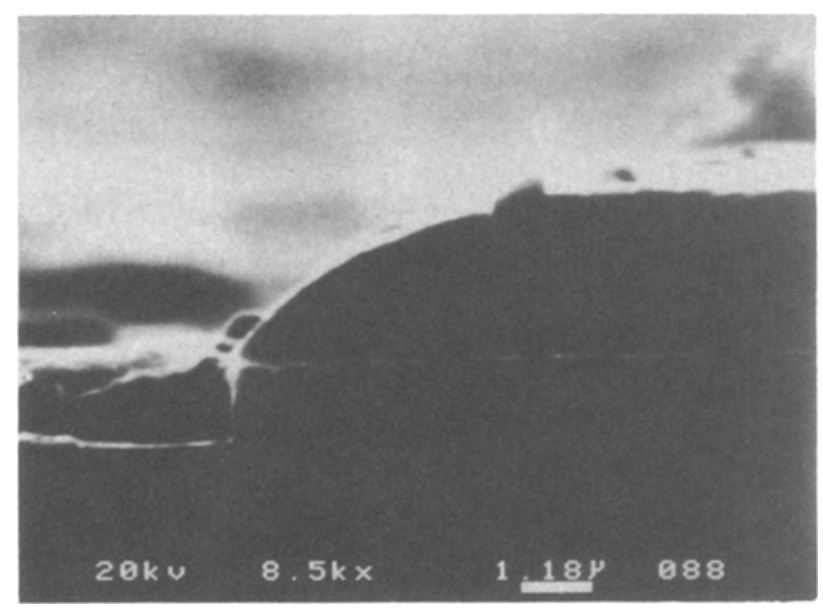

Fig. 8. SEM micrograph of ion-milled trench in Corning 7059 glass. Note a trench profile with vertical sidewalls was produced with this dry etch process.

hang. This made the lift-off process considerably more difficult and resulted in nonuniformities at the edges of the metal lines. A combination of dry and wet etching or plasma etching is expected to yield vertical trench profiles with some photoresist overhang. Optimization of the dry etching process to form trenches in the 7059 glass has not been completed.

Electrical characterization.-Calculated sheet resistances for the augmented electrode structure fabricated with both high- and low-resistivity ITO are shown in Fig. 9. The three curves showing the effect of bus metal thickness on sheet resistance were calculated assuming ideal parallel resistors and aluminum as the bus metal. Based on these results, bus metal thicknesses greater than $250 \mathrm{~nm}$ would be sufficient to achieve composite sheet resistances less than $1 \Omega / \square$. Also, for bus metal thicknesses greater than $500 \mathrm{~nm}$, the composite line resistance is relatively invariant with respect to ITO sheet resistance and ITO quality. This implies that very thin ITO films could be employed and that variations in ITO conductivity across a panel would have little effect on the composite line resistance. In short, Fig. 9 shows that the augmented electrode structure provides desirable process latitude regarding compositional and thickness variations involved in ITO preparation.

Figure 10 shows the augmented and ITO sheet resistances of electrode structures fabricated with $\mathrm{Al}-\mathrm{Ti}$ as the

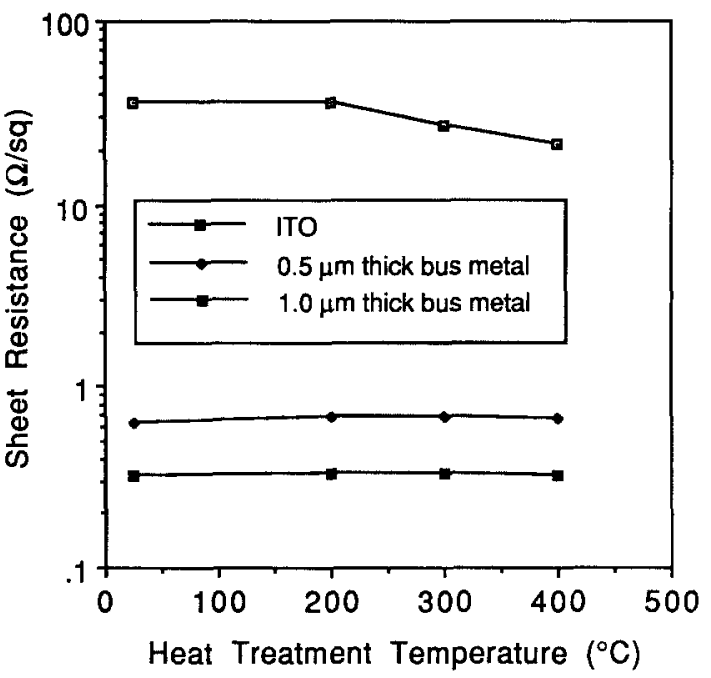

Fig. 10. Sheet resistance of ITO and augmented electrodes fabricated with an Al-Ti bus as a function of heat-treatment temperature.

bus metallization system. This figure shows that the ITO sheet resistance decreased with increasing annealing temperatures, whereas the augmented electrode sheet resistance was relatively independent of annealing temperature. The ITO sheet resistance was approximately half of the asdeposited value after annealing in vacuum at $400^{\circ} \mathrm{C}$ for $0.5 \mathrm{~h}$. Once again this demonstrates the relative insensitivity of the composite line resistance to ITO quality. It also suggests that interfacial reactions were minimized with this structure during heat-treatment. A similar set of results was obtained for the augmented electrode structures fabricated with a Ti-Ag-Ti trench metallization system, as shown in Fig. 11. It appears here that the composite line resistance is even more insensitive to heat-treatment temperature compared to the Al-Ti metallization system where no interfacial reactions occurred between the bus metal and the ITO. For both metallization schemes, augmented electrode sheet resistances approaching $0.1 \Omega / \square$ were realized.

Figure 12 shows the contact resistance of the four different metallization systems used in the augmented electrode structure after heat-treatment at $400^{\circ} \mathrm{C}$. For the aluminum and silver metallizations, the three bars correspond to three different metal thicknesses: (i) $0.25 \mu \mathrm{m}$, (ii) $0.5 \mu \mathrm{m}$, and (iii) $1.0 \mu \mathrm{m}$, and the three bars for the Al-Ti and Ag-Ti

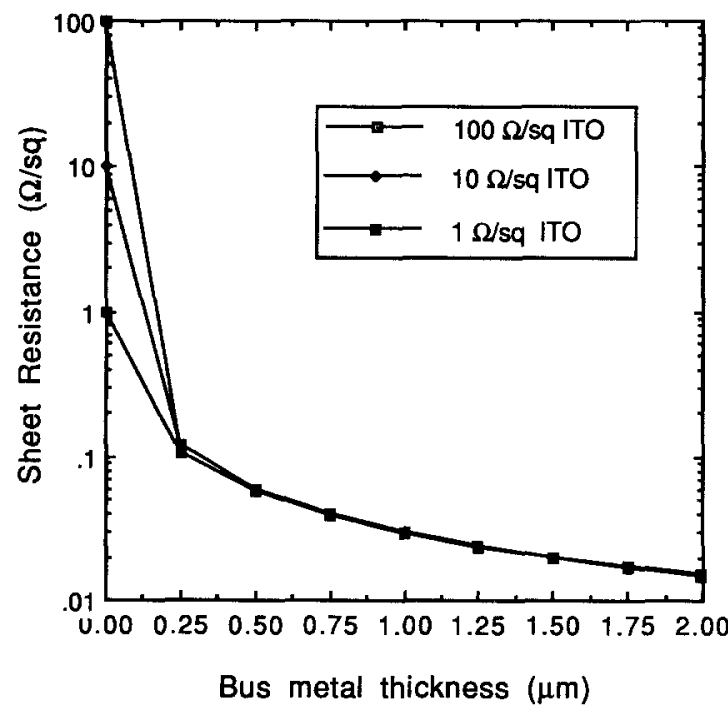

Fig. 9. Sheet resistance of augmented electrode as a function of bus metal thickness.

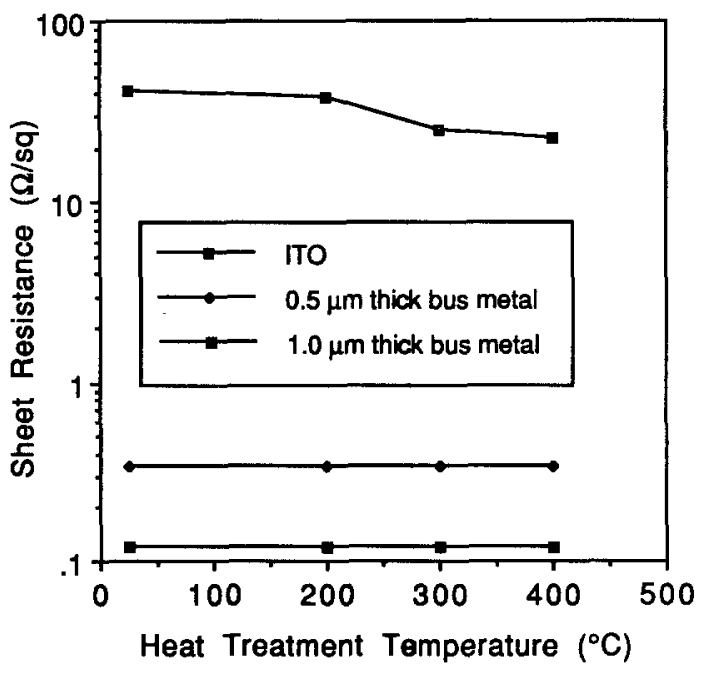

Fig. 11. Sheet resistance of ITO and augmented electrodes fabricated with an $\mathrm{Ag}-\mathrm{Ti}$ bus as a function of heot-treatment temperature. 


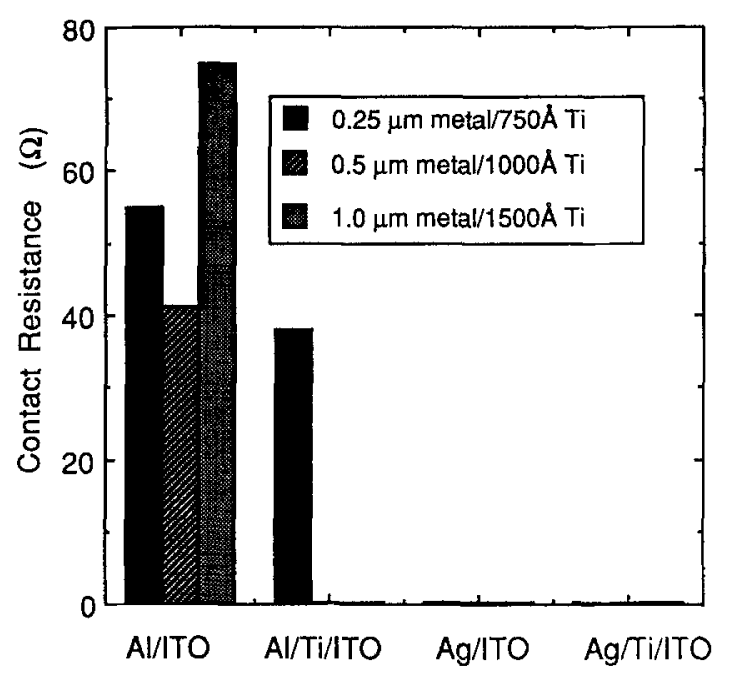

Fig. 12. Contoct resistance of augmented electrodes after heattreatment at $400^{\circ} \mathrm{C}$.

metallizations correspond to three different Ti film thicknesses in the structure: (i) 750, (ii) 1000 , and (iii) $1500 \AA$, respectively. In the Al-ITO system, contact resistances as large as $80 \Omega$ were observed for contact areas measuring $1.6 \times 10^{3} \mu \mathrm{m}^{2}$. However, extremely low contact resistances, on the order of 1-2 $\mathrm{m} \Omega$, were observed for the Ag-ITO system. This suggests that interfacial reactions between the $\mathrm{Al}$ and ITO had occurred during heat-treatment at these temperatures and the reactions between $\mathrm{Ag}$ and ITO were less pronounced.

Thin films of titanium were employed to minimize interfacial reactions between the bus metal and the ITO. The effectiveness of these thin Ti layers in preventing undesirable interfacial reactions is shown in Fig. 12 as well. In the Al-Ti-ITO system, the thin Ti layers ( $750 \AA$ thick) did little to prevent interdiffusion and interfacial reactions between the aluminum and ITO, as indicated by the high contact resistance measured ( $40 \Omega$ for a contact area of $1.6 \times 10^{3} \mu \mathrm{m}^{2}$ ). However, thicker Ti films (100 and $150 \mathrm{~nm}$ ) were much more effective in reducing the contact resistance in the augmented electrode structure. These results appear to be consistent with those reported in the literature for Al-Ti contact metallurgies in VLSI applications (14). Here it was reported that $600 \AA$ of $\mathrm{Ti}$ was consumed by reaction with aluminum to form $\mathrm{TiAl}_{3}$. This resulted in a corresponding increase in contact resistance. In the present study, it is likely that the thin Ti layer was totally consumed by reaction with $\mathrm{Al}$, which can then readily diffuse through the $\mathrm{TiAl}_{3}$ layer and react with the ITO. The thin Ti layers in the Ag-Ti-ITO system appeared to have little effect on the contact resistance, as might be expected since the Ag-ITO system itself exhibited very low contact resistances, on the

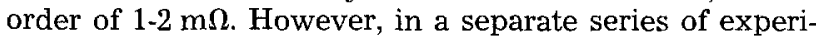
ments using very thin titanium and silver films, some interfacial reaction was observed at temperatures as low as $125^{\circ} \mathrm{C}$, as evidenced by an increase in equivalent sheet resistance for corresponding thicknesses of metal.

The high contact resistances observed for the Al-ITO system and the Al-Ti-ITO system with thin titanium can at least be partially explained in terms of interfacial reduction reactions occurring at these temperatures. If $\operatorname{In}_{2} \mathrm{O}_{3}$ and $\mathrm{SnO}_{2}$ are partially reduced by the aluminum bus metallization and the rate is adequate, a thin layer of $\mathrm{Al}_{2} \mathrm{O}_{3}$ can form, leading to the high contact resistances observed. Similar reduction reactions have been observed in ITO (8), where oxygen-deficient yttria has reduced the ITO during deposition and actually caused line blackening of the transparent electrodes. Since ITO has a relatively high oxygen deficiency to start with, a small amount of oxygen deficiency induced by such a reduction reaction can cause the ITO to turn black. In the case of the bus metal-ITO systems investigated in the present study, the oxides of the bus metal in contact with the ITO would have to be more stable than $\mathrm{In}_{2} \mathrm{O}_{3}$ or $\mathrm{SnO}_{2}$ itself.

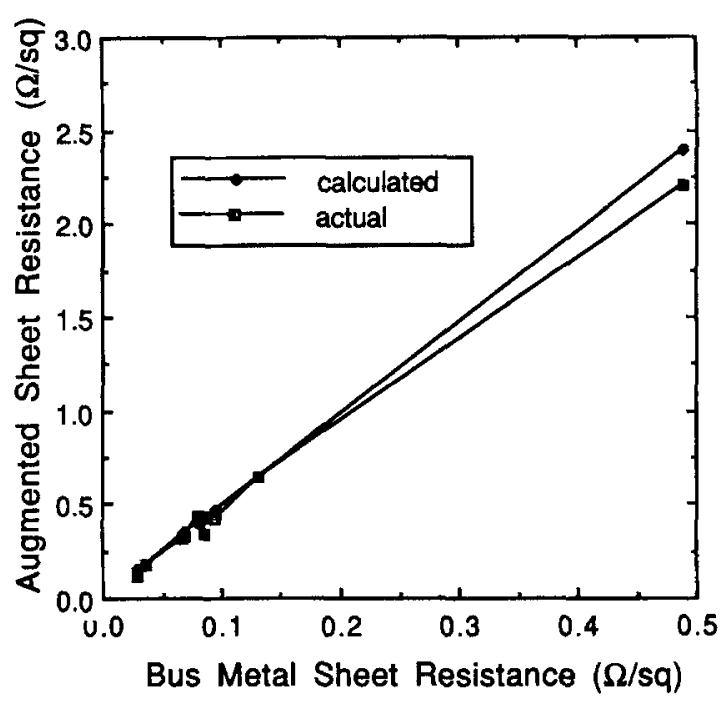

Fig. 13. Augmented electrode sheet resistance as a function of bus metal sheet resistance.

The standard free energies of formation for the three different displacement reactions possible with these metallization systems are shown below

$$
\begin{aligned}
& 4 / 3 \mathrm{Al}+2 / 3 \mathrm{In}_{2} \mathrm{O}_{3}=4 / 3 \ln +2 / 3 \mathrm{Al}_{2} \mathrm{O}_{3} \quad \Delta G^{\circ}=-248 \mathrm{kcal}[1] \\
& \mathrm{Ti}+2 / 3 \ln _{2} \mathrm{O}_{3}=4 / 3 \mathrm{ln}+\mathrm{TiO}_{2} \quad \Delta G^{\circ}=-72 \mathrm{kcal} \\
& 4 \mathrm{Ag}+2 / 3 \ln _{2} \mathrm{O}_{3}=4 / 3 \ln +2 \mathrm{Ag}_{2} \mathrm{O} \quad \Delta G^{\circ}=+130 \mathrm{kcal} \mathrm{[3]} \\
& 4 / 3 \mathrm{Al}+\mathrm{SnO}_{2}=\mathrm{Sn}+2 / 3 \mathrm{Al}_{2} \mathrm{O}_{3} \quad \Delta G^{\circ}=-252 \mathrm{kcal} \quad \text { [4] } \\
& \mathrm{Ti}+\mathrm{SnO}_{2}=\mathrm{Sn}+\mathrm{TiO}_{2} \quad \Delta G^{\circ}=-79 \mathrm{kcal} \\
& 4 \mathrm{Ag}+\mathrm{SnO}_{2}=\mathrm{Sn}+2 \mathrm{Ag}_{2} \mathrm{O} \quad \Delta G^{\circ}=+122 \mathrm{kcal}
\end{aligned}
$$

The reactions indicate that the aluminum and titanium can reduce both $\mathrm{In}_{2} \mathrm{O}_{3}$ and $\mathrm{SnO}_{2}$ at these temperatures, whereas the silver bus metallization cannot reduce these oxides. These reactions also show that there is a much larger driving force for the aluminum reduction reaction to occur than the titanium reaction to occur, which is consistent with the contact resistances shown in Fig. 12. The extent of interdiffusion of the different metals into the ITO during heat-treatment has not yet been determined. However, it is believed that the formation of an oxide layer at the metal-ITO interface would reduce the migration of the metals. It is also possible that other barrier metals such as chromium, that have an oxide stability similar to ITO, may be better suited in these applications. Also, the use of refractory metals as diffusion barrier films may be advantageous, particularly if their corresponding oxides are not as stable as $\operatorname{In}_{2} \mathrm{O}_{3}$ and $\mathrm{SnO}_{2}$ at these temperatures.

Figure 13 shows the effect of the bus metal sheet resistance on the augmented electrode sheet resistance. Here, it is shown that as the bus metal sheet resistance is increased, or metal thickness decreased, there is a larger deviation from the calculated sheet resistance of the augmented structure, which is based on ideal parallel resistors. This suggests that as the conductive bus metal thickness $\left(t_{x}\right)$ decreases, the ratio $\left(\Delta t_{x} / t_{x}\right)$ will increase for a given reacted layer thickness, where $\left(\Delta t_{x}\right)$ is the change in bus metal thickness due to interfacial reactions with the titanium diffusion barrier. Even if the resulting intermetallic compounds are conductive, either intrinsically or due to porosity, its resistivity will be greater than that of the pure metals and the composite resistance will increase. Also, it should be noted that the ideal-calculated curve for the augmented electrode sheet resistance has a slope of 5 , which is the aspect ratio of the linewidths for these composite electrodes.

\section{Conclusions}

A high-conductivity electrode system for thin film electroluminescent displays has been demonstrated, where 
the low conductivity transparent electrodes have been augmented by high conductivity buses of aluminum or silver. These electrode systems employing $\mathrm{Al}-\mathrm{Ti}$ and $\mathrm{Ag}-\mathrm{Ti}$ contact metallurgies lowered the sheet resistance by two orders of magnitude relative to the unaugmented ITO electrodes and yielded absolute values on the order of $0.1 \Omega / \square$. This represents a significant improvement in sheet resistance and will permit the fabrication of large-area TFEL displays without the present limitations placed on the current state-of-the-art transparent electrodes.

\section{Acknowledgments}

Appreciation is extended to the Electronics Technology and Devices Laboratory of the U.S. Army, for support of this work which was initiated under the Summer Faculty Research and Engineering Program. The authors would also like to thank Mr. Richard C. Piekarz for his valuable assistance in etching and patterning the glass.

Manuscript submitted Feb. 12, 1991; revised manuscript received March 1, 1991. This was Paper 627 presented at the Seattle, Washington, Meeting of the Society, Oct. 14-19, 1990.

The University of Rhode Island assisted in meeting the publication costs of this article.

\section{REFERENCES}

1. K. L. Chopra, S. Major, and D. K. Pandya, Thin Solid Films, 102, 1 (1983).

2. R. Mach and G. O. Muller, Phys. Status Solidi, 69, 11 (1982).

3. R. Tueta and M. Braguier, Thin Solid Films, 80, 143 (1981).

4. O. Sahni, P. M. Alt, D. B. Dove, W. E. Howard, and D. J. McClure, Biennial Display Research Conference, p. 154 (1980).

5. D. B. Fraser and H. D. Cook, This Journal, 119, 1368 (1972).

6. I. Lubezky, O. Marcovitch, Z. Klein, and H. Zipin, Thin Solid Films, 148, 83 (1987).

7. R. D. Ketchpel and R. Wu, Japan Display '86, p. 258 (1986).

8. M. P. R. Panicker and W. F. Essinger, This Journal, 128, 1943 (1981)

9. R. W. Bower, Appl. Phys. Lett., 23, 99 (1973)

10. K. Nakamura, S. S. Lau, M. A. Nicolet, and J. W. Mayer ibid., 28, 277 (1976).

11. C. Y. Ting and B. L. Crowder, This Journal, 129, 2590 (1982).

12. D. J. Sharp, J. Vac. Sci. Technol., 16, 204 (1979).

13. D. L. Meier, R. B. Campbell, J. R. Davis, P. Rai-Choudhury, and L. J. Sienkiewicz, IEEE 30th Electronics Components Conference, p. 904 (1982).

14. P. M. Hall and L. W. Condra, IEEE 29th Electronics Components Conference, p. 355 (1979).

\title{
A Study on Electroplated Cathodes and Their Mercury Process for Plasma Display Panel
}

\author{
Ichiro Koiwa, Yoshitaka Terao, and Hideo Sawai \\ Oki Electric Industry Company, Limited, Hybrid Microelectronics Department Research Laboratory, 550-5 \\ Higashiasakawa-cho, Hachioji-shi, Tokyo 193, Japan
}

\section{ABSTRACT}

Effect of Co-W electroplating on the conventional Ni thick film cathode and $\mathrm{Hg}$ immersion process on discharge characteristics were investigated. The $\mathrm{Co}-\mathrm{W}$ alloy, containing 16 atoms percent ( 38 weight percent) were plated for various times (from 1 to $15 \mathrm{~min}$ ) after all firing processes. The coverage of $\mathrm{Co}-\mathrm{W}$ plated film increased with increasing plating time, and after plating for $15 \mathrm{~min}$ the whole surface was covered. By Co-W plating, the discharge current, brightness, and luminous efficiency improved. However, the discharge characteristics did not depend on plating time; the plated cathodes showed similar discharge characteristics. The electroplating method was effective for both fabrication of cathode electrodes as well as the evaluation of cathode material, because it became unnecessary to prepare thick film paste with high reliability. The new mercury process, immersion of the cathode in mercury, was useful for electroplated cathodes. Since the surface of the electroplated cathode was active, mercury was reacted with it. The discharge characteristics of the panel with the new $\mathrm{Hg}$ process are the same as that with conventional one. Therefore, the new process is not only low cost but also has intrinsic advantages, because it used an active surface that had intrinsic properties of electroplated film. It was concluded from the investigation that the electroplating of the cathode electrode and the process of Hg-immersion are useful methods of preparation and evaluating of the cathode electrode of the plasma display panel.

Many types of flat panel display are being built (1). Since the dc-type plasma display panels (PDP) have advantages, such as ease of making large panels and mass production (2), many workers are investigating them.

The display system of the dc-type PDP is as follows. High voltage is applied between anodes and cathodes to produce plasma discharge. The plasma discharge is selfemission, and its response is very fast. The above properties are advantageous for display devices. As the cathodes of the dc-type plasma display panels are exposed in the discharge space, the discharge characteristics are greatly influenced. Therefore, the material of the cathode is very important.

According to previous investigation (3), the following five conditions are required for cathode materials: (i) low work function to lower driving voltage; (ii) chemically stable and easy to treat; (iii) low sputtering yield to lengthen life span; (iv) not being affected by the fabrication process of the panel; and $(v)$ applicable to large panel.

Now, according to conditions (ii), (iv), and (v), the nickel thick film prepared by the screen printing method was used as the cathode electrode. However, from the viewpoint of condition (i), nickel is not suitable because of its high work function value, $4.84 \mathrm{eV}$. Moreover, from the viewpoint of condition (iii), the nickel is not suitable, the addition of mercury $(\mathrm{Hg})$ suppresses the sputtering and lengthens the life span. Therefore, to lower driving voltage and to lengthen life span, the development of new cathode materials is required $(3,4)$. From conditions $(i v),(v)$ and accumulated technologies, the screen-printing method is the most suitable for the preparation of the cathode electrode. However, the firing processes of more than $500^{\circ} \mathrm{C}$ limits the kinds of applicable metal. Since it is difficult to prepare the paste with high reliability, avoiding oxidation, and aggregation, there are only a few reports for aluminum (Al) (3) and lanthanum boride $\left(\mathrm{LaB}_{6}\right)(3,4)$. Therefore, a new preparation method for the cathode is necessary in order to investigate new cathode materials. In this paper, the conventional $\mathrm{Ni}$ thick film cathode is fabricated in advance as the underlayer cathode. Then, after the complete firing processes, the cathode electrode is electroplated. This method makes it possible to investigate new cathode materials using accumulated technologies. Moreover, the new mercury process to lengthen life span, immersion in mercury, is reported.

\section{Experimental}

Figure 1 shows the conventional fabrication process. On the window panel, the anode electrode was vacuum evaporated indium tin oxide (ITO). Next, the anode lead and 